\title{
Pin-bearing mechanical behaviour of continuous reinforced Kevlar fibre composite fabricated via fused filament fabrication
}

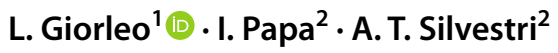

Received: 13 September 2021 / Accepted: 4 January 2022 / Published online: 28 January 2022

(c) The Author(s) 2022

\begin{abstract}
In this study, the pin bearing behaviour of a 3D printed composite material with Kevlar reinforcement was analysed. Three different experimental tests were designed to determine the effects of fibre orientation, layer design, and fibre distribution along the specimen thickness. Furthermore, the pin-bearing strength and stiffness were analysed using statistical methods as analysis of variance. The results indicate a significant increase in bearing strength and stiffness for at least two fibre orientations, i.e. $0^{\circ}$ and $90^{\circ}$ with respect to the pin displacement. The results also highlight a no significant variation of strength and stiffness for parts produced adopting a mixed or single fibre orientation; finally, the findings do not indicate any significant influence of the fibre layer position inside the specimen, i.e. this parameter does not limit the freedom when designing a fibre-reinforced part.
\end{abstract}

Keywords Fibre-reinforced composite $\cdot$ Fused filament fabrication $\cdot$ Mechanical behaviour $\cdot$ Bearing

\section{Introduction}

Continuous reinforced fibre composite (CRFC) materials are widely used due to their low weight, high mechanical performance, low production and maintenance costs, and corrosion resistance $[1,2]$. The use of long fibres leads to the generation of a highly anisotropic material that can be used to exploit the capability of the alignment of the fibres. Given this feature, it is possible to significantly improve the mechanical performance mainly in the direction parallel to the applied load $[3,4]$. Hence, there is an increase in additive manufacturing (AM) techniques because they can customise layer-by-layer printed products and can realise complex objects in a single step, thereby avoiding the assembly stage $[5,6]$. Among all the AM techniques, the most common is fused filament fabrication (FFF) as it is a cost-effective, almost-zero-waste, and user-friendly approach [7, 8]. Therefore, composite materials produced using this method are

\section{Giorleo}

luca.giorleo@unibs.it

1 Department of Mechanical and Industrial Engineering, University of Brescia, Brescia, Italy

2 Department of Chemical, Materials and Industrial Production Engineering, University of Naples Federico II, Naples, Italy widely characterised and investigated via tension, flexural, compression, impact, and shear tests.

In literature, several characterizations have been performed on CRFC reinforced with carbon, glass and Kevlar fibres printed with FFF additive technology. The main mechanical behaviour evaluated is the response to the tensile test and the results founded could be resumed as follow: higher performances with carbon reinforcement respect to glass and Kevlar [9, 10]; fiber layer position distribution does not affect the tensile strength [11] and elastic modulus [12]; presence of voids occurs with the increase of consecutive fibres layer [13]; best reinforcements achievable when fibres are oriented parallel to the loading direction [14]; CRFC parts produced with additive manufacturing technology has lower properties respect to traditional methods because of layering production process $[15,16]$; it exists a trade off in terms of quality comparing long and short fibre [17]; highest rigidity achievable with layers of matrix and fibres alternated of $\pm 45^{\circ}$ respect to the load direction [18].

Despite these important results, few studies are available on others mechanical behaviours of CRFC produced with AM such as bearing strength, parameter fundamental in designing reversible joints. Pin bearing test is designed to evaluate the response of a plate, fastener, and hole to stress. The test establishes a value for the bearing stiffness and bearing strength for the joint. The bearing stiffness is the 
linear proportionality between bearing stress and bearing strain, and the bearing strength is the amount of bearing stress that the test specimen can support before fracture. In literature, pin-bearing behaviour was investigated on CRFC samples produced with conventional technique as vacuum bagging [19-21], woven technology [22] and hot pressing [23]. The findings concluded that bearing failure is affected by geometrical parameters, including hole diameter (D), edge distance (E), and width (W) and that, in case of carbon fibres, best results are obtained with fibres oriented along the load direction. Ascione et al. proposed a bearing strength prediction model for glass fibre reinforced composite [23]. Comparing bearing resistance of CRFC produced with additive manufacturing respect to conventional technique it was found that best results are achieved with AM if the hole is produced subsequently by drilling process $[24,25]$. The reason can be ascribed to the technological limitations of the AM process: to create a hole by an additive approach the so-called wall layers circumscribing the hole itself are mandatory. This resulted in the addition of an extra-matrix phase around the hole before printing the fiber with a consequently loss of performance.

However, it must be highlight that most of the results founded are referred to carbon fiber reinforcement but other synthetic fibers are available with interesting mechanical properties. Among these Kevlar fibres exhibits high strength-to-weight ratio, low density, better impact resistance, and higher flexibility [26-28]; moreover, other investigations concluded that Kevlar is more resistant to fatigue and it exhibits stronger abrasion resistance than carbon and glass fibres [29]. These properties lead Kevlar suitable for application in aeronautical environment.

To enrich the existing knowledge, in this study, a CRFC, with Kevlar as reinforcement and Nylon as matrix, was fabricated via FFF. The composite was characterised via a double-lap pin-bearing test. Three types of experimental tests were designed considering different parameters, i.e. the fibre orientation, layer package sequence, and fibre layer distribution along the specimen thickness. The results were consistent with those of other material characterisation tests and provided useful information with respect to fibre layer distribution for designing composite parts.

\section{Materials and methods}

\subsection{Materials and specimen design}

The specimens were printed with a Mark Two (Markforged, Watertown, MA, USA), which uses fused filament fabrication technology to fabricate parts and is equipped with two nozzles to deposit a layer of matrix and a layer of fibre. For the matrix, we used Onyx, which is a nylon matrix reinforced with micro carbon fibres [30]. Furthermore, Kevlar was used as the reinforcement. Table 1 lists the main properties of the matrix and fibre.

The specimen geometry was set based on ASTM D5961/D5961M-10 [31]. The geometry was first designed in SolidWorks and then converted into an STL file. Figure 1 shows the main dimensions in $\mathrm{mm}$ of the specimens.

During the samples printing the matrix extrusion temperature was set equal to $275{ }^{\circ} \mathrm{C}$ while the fibre temperature at $255^{\circ} \mathrm{C}$; no heating procedure have been set for the bed plate. These parameters are indicated by the printing machine as optimal parameters for the printability of the selected material. Based on the performance of the 3D printer, the specimens were fabricated as a combination of 36 layers with a thickness of $0.1 \mathrm{~mm}$ each. For each layer, it was possible to set the type of material (matrix or fibre) and wire orientation. Furthermore, it was possible to set a layer package (LP) with the same material and fibre orientation.

To analyse the mechanical behaviour, three different experimental tests were designed as a function of fibre orientation, position, and LP design. In all the experiments, each test was replicated thrice. For the first and second experimental test, the specimen matrix/layer distribution was set as follows:

- An LP equal to four layers was set such that the specimen was considered as comprising nine LPs.

- All the specimens included five LPs of the matrix and four LPs of Kevlar, i.e. 20 layers of matrix and 16 layers of Kevlar. Therefore, the proportion of the fibre layer was equal to $45 \%$.

- In all the matrix LPs, a full solid infill was set and the wire orientation was equal to a sequence of $45^{\circ}$ and $135^{\circ}$.

Table 1 Mechanical properties of the matrix and reinforcement

\begin{tabular}{lll}
\hline Properties & Onyx & Kevlar \\
\hline Tensile modulus (GPa) & 2.4 & 27 \\
Tensile strength (MPa) & 40 & 610 \\
Tensile stress at failure $(\mathrm{MPa})$ & 37 & $/$ \\
Tensile strain at failure $(\%)$ & 25 & $/$ \\
Flexural modulus $(\mathrm{GPa})$ & 3 & 26 \\
Flexural strength $(\mathrm{MPa})$ & 71 & 240 \\
Flexural strain at failure $(\%)$ & $/$ & 2.1 \\
Compressive modulus $(\mathrm{GPa})$ & $/$ & 28 \\
Compressive strength $(\mathrm{MPa})$ & $/$ & 97 \\
Compressive strain at break $(\%)$ & $/$ & 15 \\
Heat-deflection temp $\left({ }^{\circ} \mathrm{C}\right)$ & 145 & 105 \\
Iozd-impact-notched $(\mathrm{J} / \mathrm{m})$ & 330 & 2000 \\
Density $\left(\mathrm{g} / \mathrm{cm}^{3}\right)$ & 1.2 & 1.2 \\
\hline
\end{tabular}


Fig. 1 Main dimensions (mm) of specimens based on ASTM D5961/D5961M-10

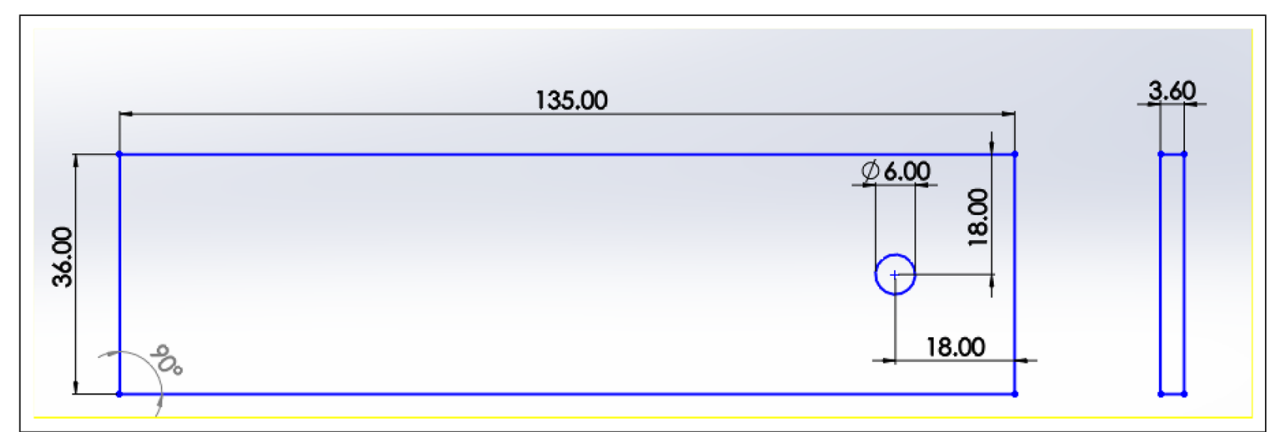

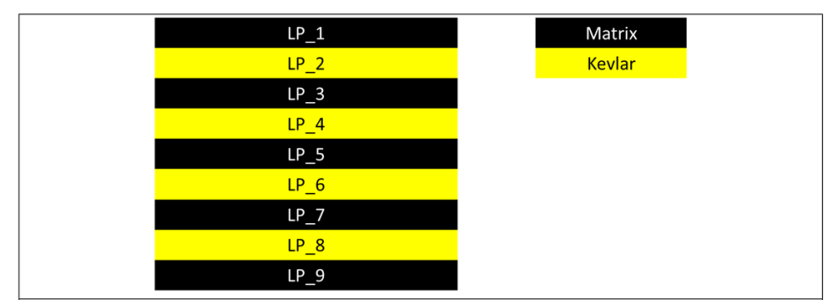

Fig. 2 Specimen cross-section configuration as a function of the layer package (LP)

Table 2 First experimental tes-fibre PL configuration as a function of fibre orientation

\begin{tabular}{llll}
\hline Layer Package & Test_0 & Test_45 & Test_90 \\
\hline LP_2 & $0^{\circ}$ & $45^{\circ}$ & $90^{\circ}$ \\
LP_4 & $0^{\circ}$ & $45^{\circ}$ & $90^{\circ}$ \\
LP_6 & $0^{\circ}$ & $45^{\circ}$ & $90^{\circ}$ \\
LP_8 & $0^{\circ}$ & $45^{\circ}$ & $90^{\circ}$ \\
\hline
\end{tabular}

Based on the aforementioned distribution, the specimen cross-section configuration is shown in Fig. 2.

In the first experiment test, we analysed the effect of fibre orientation. Three different specimen configurations were tested as a function of the fibre orientation as follows: $0^{\circ}, 45^{\circ}$, and $90^{\circ}$ with respect to the specimen length. The results were compared with those of specimen without fibres (Test_NO). Table 2 summarises each test design as a function of the LP.

In the second experimental test, we tested the effect of LP design. Four different specimen configurations were designed to analyse whether PL with single (S) or mixed (M) fibre orientation affects pin bearing behaviour. The strategy for printing fibre layers with different orientations was also tested. Table 3 presents the test configuration.

For the third experimental test, it was investigated the dimension of LP inside the specimen. Five different configurations were designed with different LP dimensions as follows: one LP with 16 layers (Test_16 L), two LPs with eight layers (Test $8 \mathrm{~L}$ ), three LPs with four layers (Test_4 L), eight LPs with two layers (Test_2 L), and 16 LPs with 1 layer (Test_1 L). To avoid any effect of orientation, Kevlar was deposited at $0^{\circ}, 45^{\circ}, 90^{\circ}$, and $135^{\circ}$. Table 4 lists the LP positions of the specimen, in particular Table 4 described layer by layer the presence of matrix (white) or fibre (yellow) and reports also the filament orientation.

\subsection{Methods}

Pin-hole tensile tests were performed using a Galdabini QUASAR 50 (Galdabini SPA, Italy, load cell of $50 \mathrm{kN}$ ). The cross-head speed was set to $3 \mathrm{~mm} / \mathrm{min}$, and a software was used to record pin displacement and stress values. The experimental setup is shown in Fig. 3a, and b illustrate the bearing test apparatus based on ASTM D 5961 [31].

After the bearing tests, bearing strength and stiffness were evaluated. Based on the data recorded via the dedicated software of the equipment, the deformation, maximum load, stiffness of the samples at the bearing, and hole resistance were determined. The bearing strength, $\sigma_{b r}$, is conventionally used to indicate the stress at the maximum load (Eq. 1):
Table 3 Second experimental test-fibre PL configuration

\begin{tabular}{lllll}
\hline Layer Package & Test 0_90_M & Test 45_135_M & Test 0_90_S & Test 45_135_S \\
\hline LP_2 & 0/90/0/90 & $45 / 135 / 45 / 135$ & $0 / 0 / 0 / 0$ & $45 / 45 / 45 / 45$ \\
LP_4 & $0 / 90 / 0 / 90$ & $45 / 135 / 45 / 135$ & $90 / 90 / 90 / 90$ & $135 / 135 / 135 / 135$ \\
LP_6 & $0 / 90 / 0 / 90$ & $45 / 135 / 45 / 135$ & $0 / 0 / 0 / 0$ & $45 / 45 / 45 / 45$ \\
LP_8 & 0/90/0/90 & $45 / 135 / 45 / 135$ & $90 / 90 / 90 / 90$ & $135 / 135 / 135 / 135$ \\
\hline
\end{tabular}


Table 4 Third experimental campaign test configuration

\begin{tabular}{|c|c|c|c|c|c|}
\hline Layer & Test_16L & Test_8L & Test_4L & Test_2L & Test_1L \\
\hline 1 & 45 & 45 & 45 & 45 & 45 \\
\hline 2 & 135 & 135 & 135 & 135 & 135 \\
\hline 3 & 45 & 0 & 45 & 45 & 0 \\
\hline 4 & 135 & 45 & 135 & 0 & 45 \\
\hline 5 & 45 & 135 & 0 & 45 & 45 \\
\hline 6 & 135 & 90 & 45 & 45 & 135 \\
\hline 7 & 45 & 0 & 135 & 135 & 135 \\
\hline 8 & 135 & 45 & 90 & 135 & 45 \\
\hline 9 & 45 & 135 & 45 & 90 & 90 \\
\hline 10 & 135 & 90 & 135 & 45 & 135 \\
\hline 11 & 0 & 45 & 45 & 135 & 0 \\
\hline 12 & 45 & 135 & 135 & 0 & 45 \\
\hline 13 & 135 & 45 & 0 & 45 & 45 \\
\hline 14 & 90 & 135 & 45 & 45 & 135 \\
\hline 15 & 0 & 45 & 135 & 135 & 135 \\
\hline 16 & 45 & 135 & 90 & 135 & 45 \\
\hline 17 & 135 & 45 & 45 & 90 & 90 \\
\hline 18 & 90 & 135 & 135 & 45 & 45 \\
\hline 19 & 0 & 45 & 45 & 135 & 135 \\
\hline 20 & 45 & 135 & 135 & 0 & 0 \\
\hline 21 & 135 & 45 & 0 & 45 & 45 \\
\hline 22 & 90 & 135 & 45 & 45 & 45 \\
\hline 23 & 0 & 45 & 135 & 135 & 135 \\
\hline 24 & 45 & 135 & 90 & 135 & 135 \\
\hline 25 & 135 & 45 & 45 & 90 & 45 \\
\hline 26 & 90 & 135 & 135 & 45 & 90 \\
\hline 27 & 45 & 0 & 45 & 135 & 135 \\
\hline 28 & 135 & 45 & 135 & 0 & 0 \\
\hline 29 & 45 & 135 & 0 & 45 & 45 \\
\hline 30 & 135 & 90 & 45 & 45 & 45 \\
\hline 31 & 45 & 0 & 135 & 135 & 135 \\
\hline 32 & 135 & 45 & 90 & 135 & 135 \\
\hline 33 & 45 & 135 & 45 & 90 & 45 \\
\hline 34 & 135 & 90 & 135 & 45 & 90 \\
\hline 35 & 45 & 45 & 45 & 135 & 135 \\
\hline 36 & 135 & 135 & 135 & 45 & 45 \\
\hline
\end{tabular}

$\sigma_{b r}=\frac{P}{D t}$

where $P$ denotes the bearing load, $D$ denotes the hole diameter, and $t$ denotes the specimen thickness. The stress-displacement curve generated from the data can be used to evaluate the bearing stiffness of the samples $\left(K_{p}\right)$. The stiffness is determined from the stress-strain curve with a gradient in the range of $5-5.5 \%$ bearing strain, where the stress-displacement curve is relatively linear for all the specimens [32]. As example, in Fig. 4 a graphic diagram of the stiffness measurement on a classic Stress-pin displacement curve is shown.

The second experimental test involved macrographic section analysis. The tests were performed using a Hirox digital microscope KH 8700 ( 24 fps and $1200 \times 1600$ pixel resolution). Furthermore, Analysis of Variance (AnoVa) was used to analyse the results obtained from each experimental test. Moreover, where possible, Tukey range test was executed too to find, for each level tested, means that are significantly different from each other.

\section{Results}

\subsection{First experimental tests}

Figure 4 shows the main results of the pin bearing tests. All the experiments exhibited good replica repetition (maximum dispersion with respect to $\sigma_{b r}$ was less than $15 \%$ ), thereby highlighting the production process and experimental robustness. As shown in Fig. 5, it is possible to observe two different material behaviours. The first material behaviour was characterized by a higher slope. This corresponded to the material with fibre orientations of $0^{\circ}$ and $45^{\circ}$ (Fig. $5 \mathrm{~b}$ and c). Furthermore, the specimen with only matrix or specimen with fibres deposited orthogonal to the pin displacement showed higher pin deformations. However, they failed at lower bearing stress.

Figure 6 shows the magnified images of the hole deformation for each test configuration. The hole deformation images confirmed that pin bearing corresponds to the first phenomena of material failure.

Table 5 shows that the fibre orientation is significant for $\sigma_{b r}$ and $K_{p}$ ( $p$ value lower than 0.05 ). Furthermore, Tukey's range test was used to identify two different groups based on bearing strength (Fig. 7a). Specifically, the mechanical behaviour of specimens with fibre orientation orthogonal to the pin displacement (Test_90) was similar to that of specimens without fibre. With respect to stiffness (Fig. 7b), the results of Test_0 significantly differed from those of other fibre orientations.

\subsection{Second experimental test}

In the second experimental test, all experiments show good replica repetition, as shown in Fig. 8, with a maximum dispersion of $\sigma_{\mathrm{br}}$ corresponding to $16 \%$. Additionally, all the specimens failed, as shown in Fig. 9. However, as shown in Fig. 8, specimens with $0^{\circ}-90^{\circ}$ fibre orientation failed at lower pin displacements (approximately $5 \mathrm{~mm}$ ) when compared to specimens with fibre orientation of $45^{\circ}-135^{\circ}$ (approximately $10 \mathrm{~mm}$ ). Furthermore, specimens with $0^{\circ}-90^{\circ}$ fibre orientation exhibited higher bearing strength 
Fig. 3 Pin bearing experimental setup (a) and test apparatus b
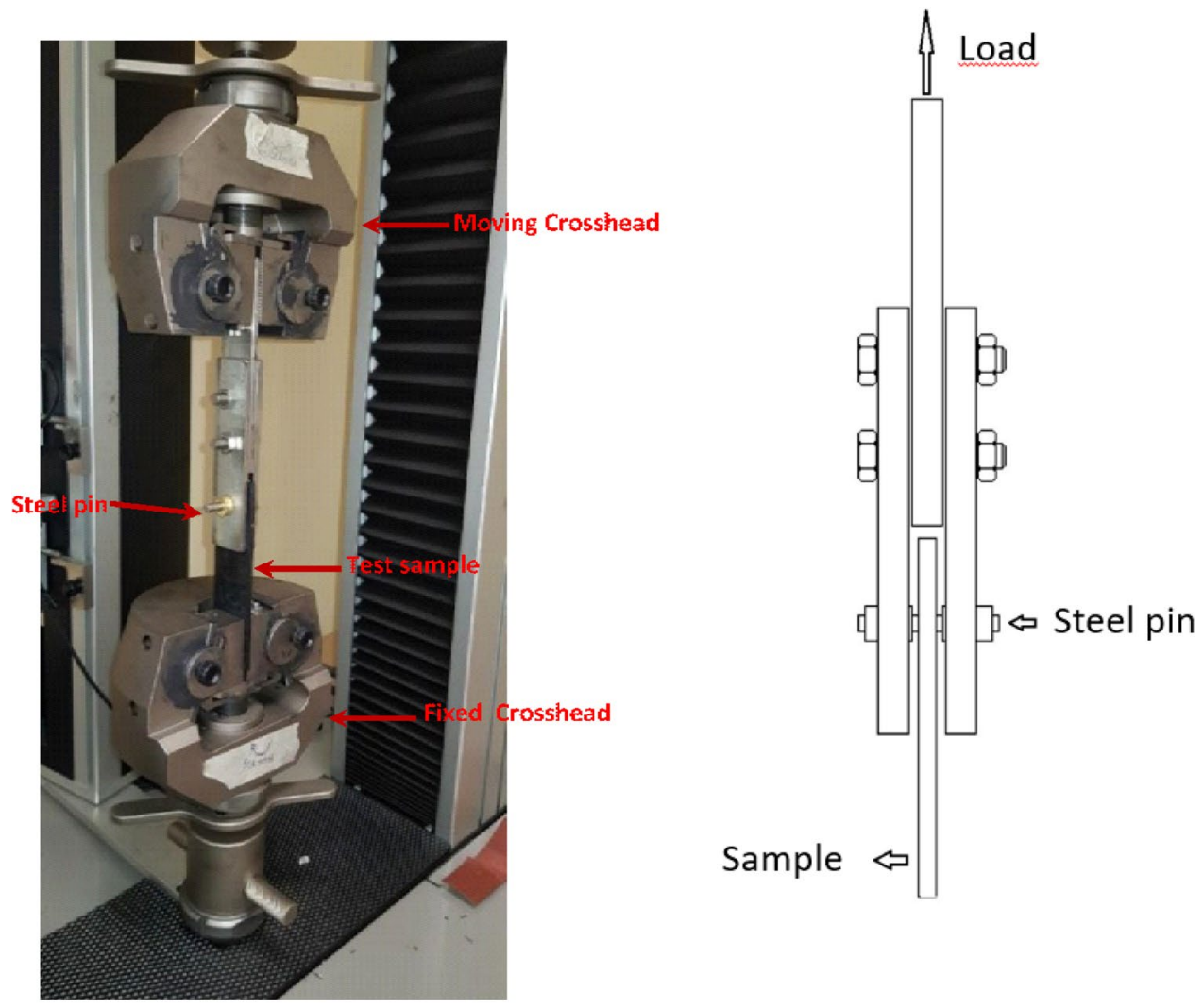

(a)

(b)
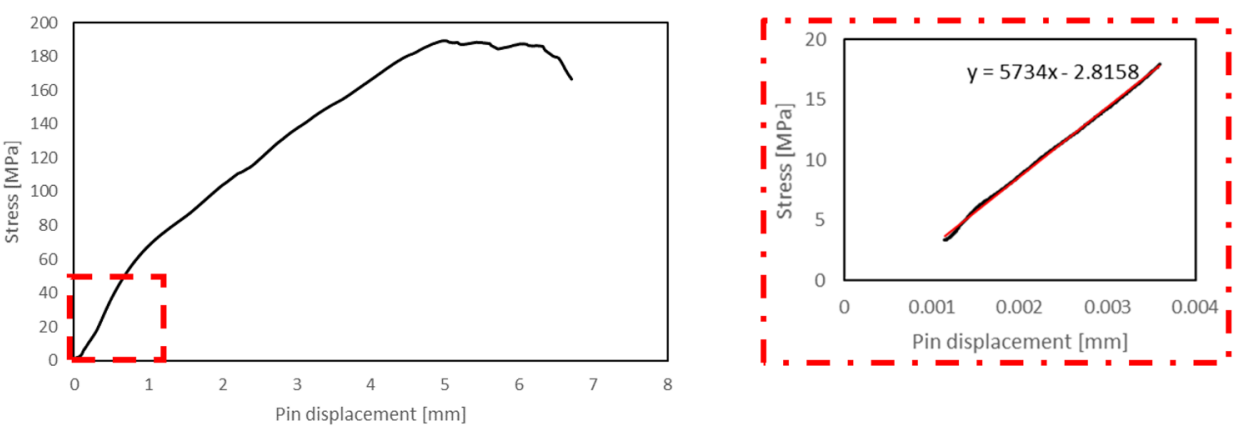

\section{$K_{b}=5734$}

Fig.4 Mode of bearing stiffness, $K_{b}$, evaluation from Stress-Pin displacement curve

when compared to specimens with fibre orientation of $45^{\circ}-135^{\circ}$. Furthermore, there was no significant difference in the shapes of the curves of mixed and separated distributions.

The analysis of variance is shown in Table $6 \mathrm{a}$ and $\mathrm{b}$, and it confirms that only fibre orientation significantly affects $\sigma_{\mathrm{br}}$ and $\mathrm{K}_{\mathrm{p}}$. This is also shown in Fig. 10a and b, where the average maximum values of $\sigma_{b r}$ is $K_{p}$ for the $0^{\circ}-90^{\circ}$ specimens with single and mixed layer configurations are observed to be $8 \%$ and $47 \%$ higher than those for the $45^{\circ}-135^{\circ}$ specimens, respectively. In the same graph, it is possible to observe that the distribution of reinforced layers in a single or mixed configuration for the same fibre orientations does not improve $\sigma_{b r}$ and $K_{p}$. Their average maximum values in these two layouts are comparable.

A macrograph of the hole of the loaded specimen is shown in Fig. 11. The pin-bearing test visibly led to buckling of the surface, and significant differences were not observed among the different types of samples. The nature of the strains in the plies is dependent on whether buckling occurs symmetrically (Fig. 11a-c) or antisymmetrically (Fig. 11d), as indicated by the dashed red line. 


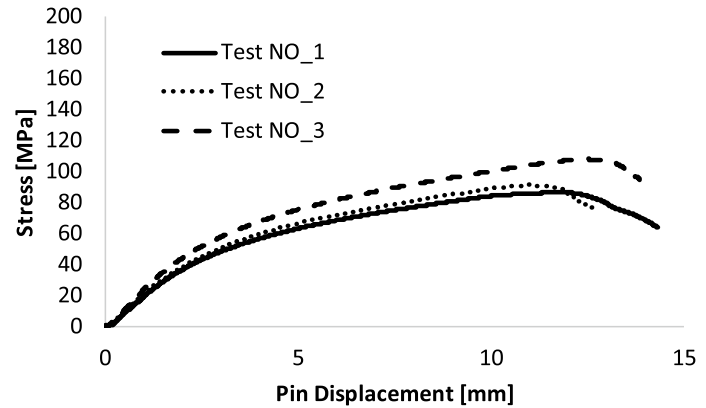

(a) Test_NO

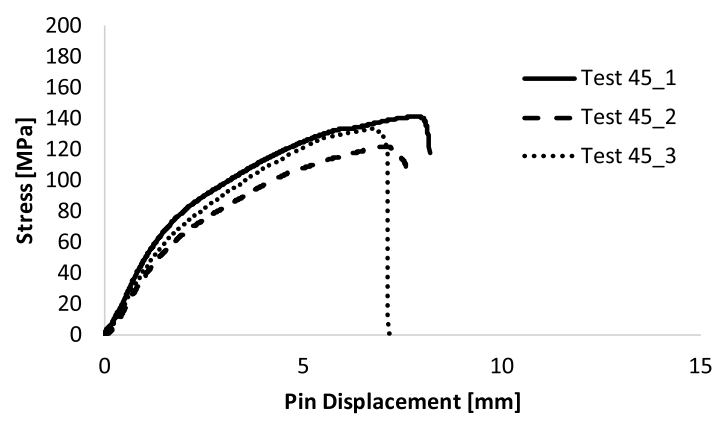

(c) Test_45

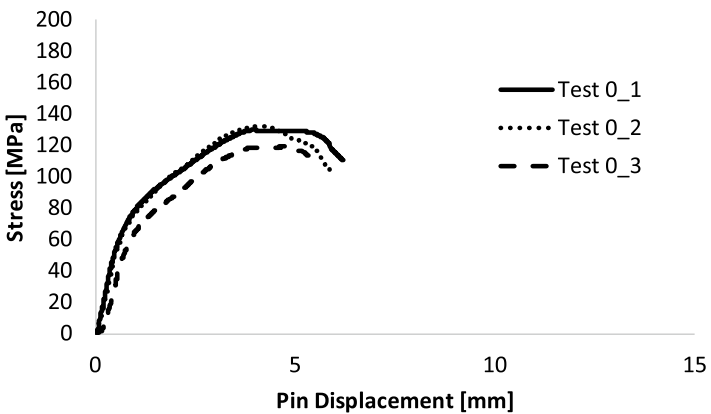

(b) Test_0

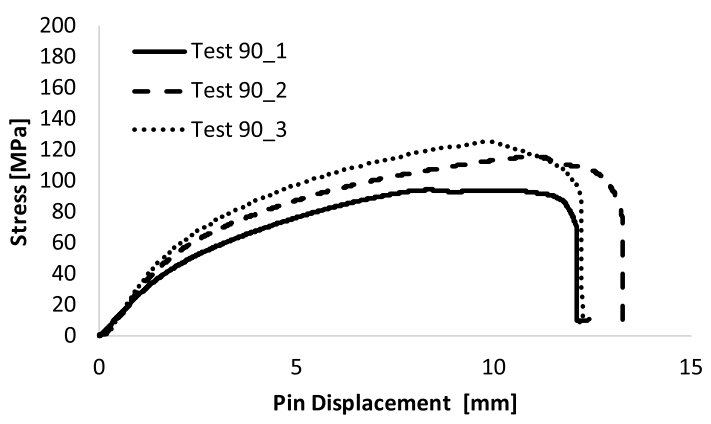

(d) Test_90

Fig. 5 Main results of the first pin bearing test

Fig. 6 First experimental testmagnified images of deformed specimens

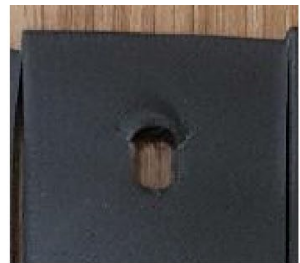

(a) Test_NO

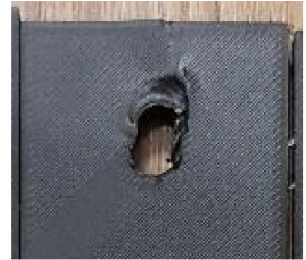

(b) Test_0

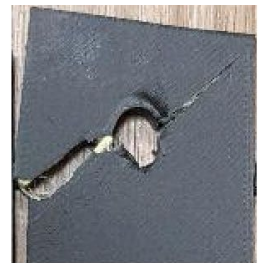

(c) Test_45

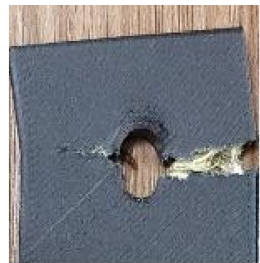

(d) Test_90
Table 5 ANOVA test results

\begin{tabular}{llr}
\hline Source & Parameter & $p$ value \\
\hline Fibre orientation & $\sigma_{b r}$ & 0.017 \\
& $K_{P}$ & $<0.005$ \\
\hline
\end{tabular}

In the symmetrical condition, tensile transverse and shear deformations are produced in the plies. In the antisymmetrical condition, only shear deformation occurs [33]. It is implicit that delamination is occasionally visible (Fig. 11, red circle) as an effect of the loading on the hole and not merely as the effect of buckling. This was confirmed in [34], where it was observed that the bearing action of the pin generates tensile interlaminar normal stresses at the hole.

\subsection{Third experimental test}

Figure 12 shows all the experimental curves for each configuration of the third experimental test. All the specimens exhibited good replica repetition, and the maximum dispersion measured for $\sigma_{b r}$ was less than $13 \%$. All the test configurations involved the same fibre orientation. Hence, it was possible to obtain the same shape for all the curves. Furthermore, there was no significant difference in the maxima values of $\sigma_{b r}$ for all the configurations. Figure 13 shows bearing failures in the third campaign.

Table 7 and Fig. 14 show the analysis of variance for the third experimental campaign. The results indicated that the distribution of the reinforced layers is not significant for $\sigma_{b r}$ and $K_{p}$ with respect to the same number of fibres and same fibre orientation. This is evidently shown in Table 7 with a $p$ value $>0.05$. Furthermore, the results in Figs. 14a and $\mathrm{b}$ 


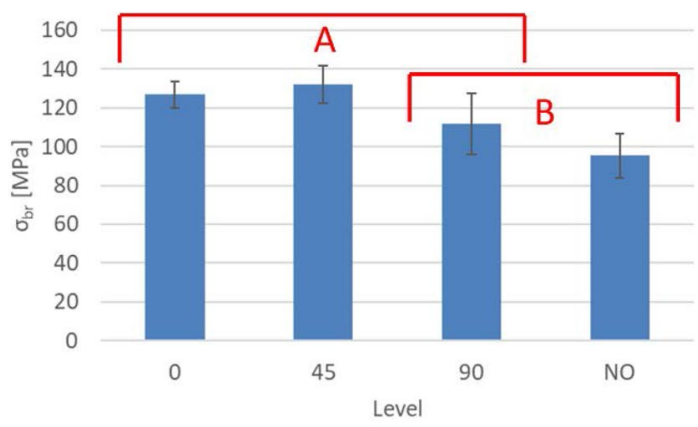

(a) $\sigma_{b r}$

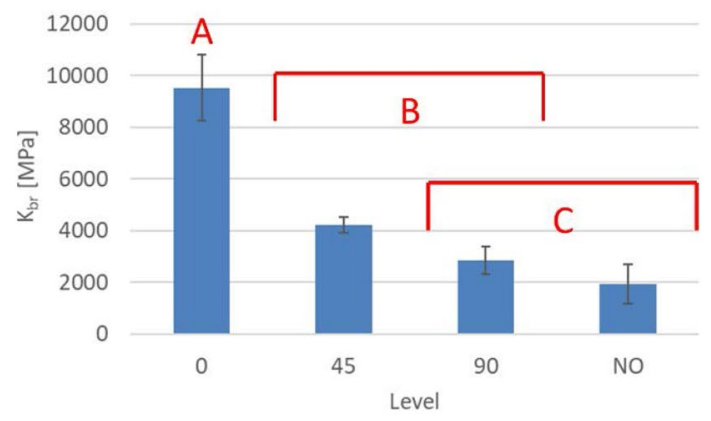

(b) $K_{p}$

Fig. 7 Tukey’s range test results and groups level founded

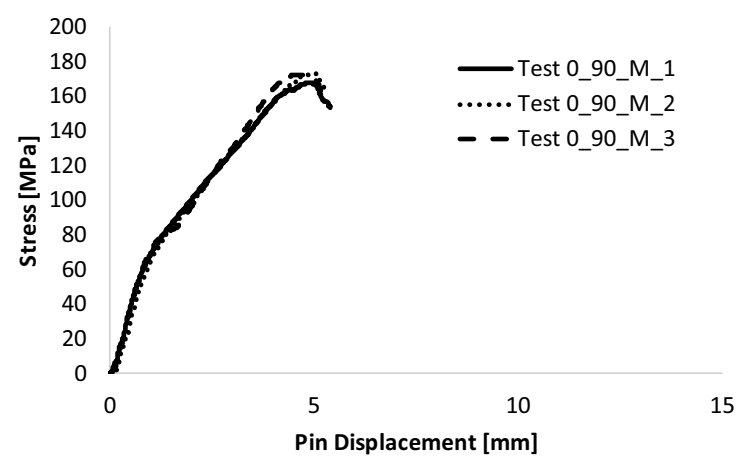

(a) Test 0_90_M

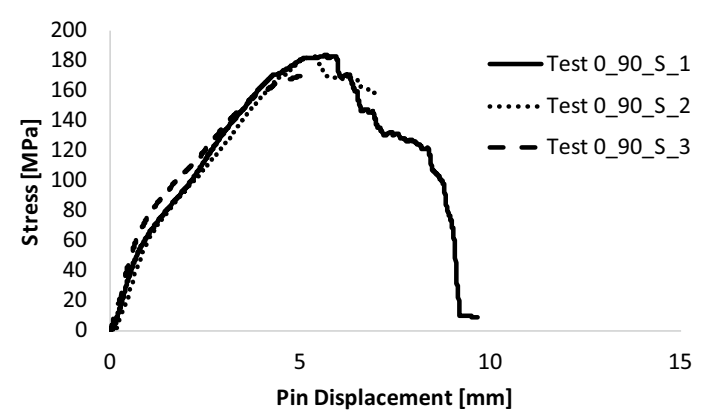

(c) Test 0_90_S

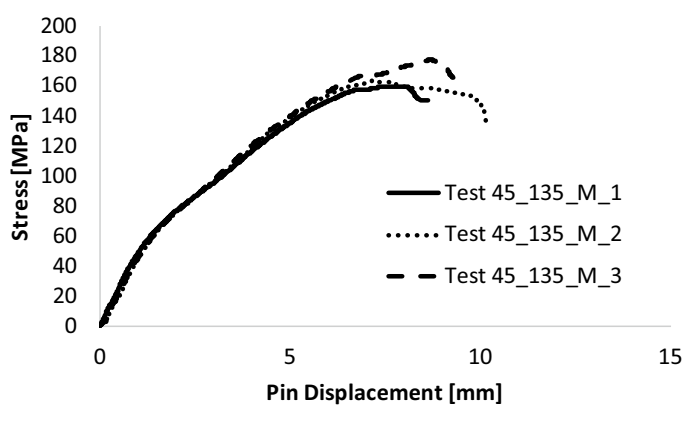

(b) Test 45_135_M

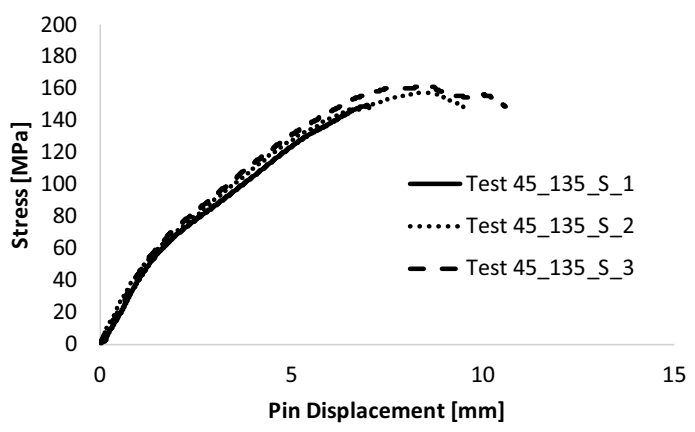

(d) Test 45_135_S

Fig. 8 Main results of the second experimental pin bearing test

Fig.9 Second experimental test-magnified images of deformed specimens
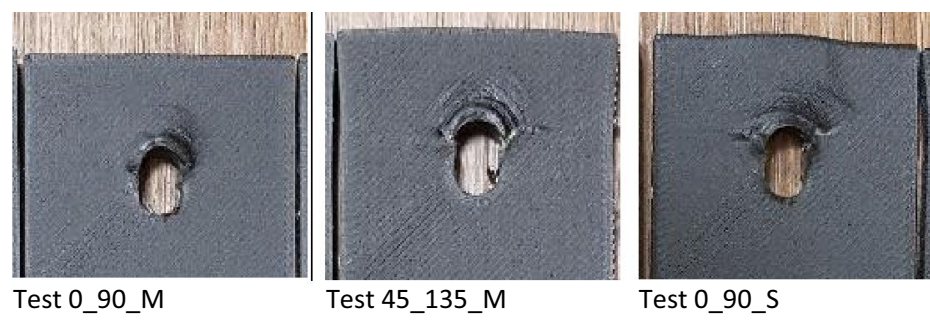

Test 0_90_S

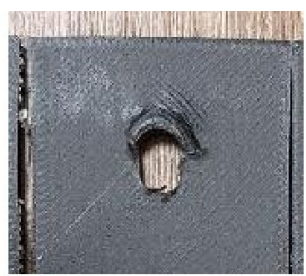

Test 45_135_S 
Table 6 Statistical analysis of the second experimental test

\begin{tabular}{lclc}
\hline Source & $p$ value & Source & $p$ value \\
\hline Fibre orientation & 0.01 & Fibre orientation & 0.005 \\
LP design & 0.716 & LP design & 0.517 \\
Interaction & 0.056 & Interaction & 0.398 \\
(a) $\sigma_{b r}$ ANOVA test results & (b) $K_{P}$ ANOVA test results
\end{tabular}

indicate that there is no evidence of a relationship between the distribution along the thickness of the fibre layers and changes in $\sigma_{b r}$ and $K_{p}$.

\section{Discussion}

The analysis of the results of the study are summarized below:

- The first experimental results were for mono-directional reinforced specimens and unreinforced specimens. Specifically, similar results were obtained in terms of $\sigma_{b r}$ for fibre orientations of $0^{\circ}$ and $45^{\circ}$. Furthermore, the fibre orientation of $90^{\circ}$ can be considered as the boundary between the two groups, as determined through the Tukey test (Fig. 7). The results were in contrast to those obtained in [11]. The specimen with fibres oriented at $0^{\circ}$ exhibited optimal performances during the tensile test. This difference in performance is related to premature failure due to buckling of $0^{\circ}$ fibres during the pin bearing test and complex stress that the pin transfers to the plate. This can occur not only in the load direction. Hence, this is contrary to [11], which states that $90^{\circ}$ fibres cannot improve mechanical properties during the tensile test. Furthermore, high stiffness was observed for fibres oriented parallel to the load direction. However, the stiff- ness decreased for the fibre orientation of $45^{\circ}$ during the tensile test [11]. Specifically, it was only $8.3 \%$ higher than that of the unreinforced configuration. In the current study, for fibre deposition at $45^{\circ}$, the bearing stiffness was $+54 \%$ and $-56 \%$ with respect to only polymeric and $0^{\circ}$ configurations, respectively.

- The second experimental test indicated that the bearing strength and stiffness are significant when the fibre is oriented in more than one direction. Specifically, with respect to the bearing strength, the Tukey test in the first experimental campaign highlighted that all the samples with fibres belong to the same group (Fig. 6). Conversely, the ANOVA results of the second campaign (Fig. 10c) demonstrate a significant difference between the two tested sets. In particular, it was observed that samples with fiber along 0 and $90^{\circ}$ has higher stiffness and resistance to bearing strength, this phenomenon is coherent with the results obtained by [11] in case of tensile test. However, respect to [11] better results have been achieved with Test 0-90 mixed or simple comparing with results of Test $0^{\circ}$; the reason is caused by the stress distribution that in pin bearing is not constant but varies from zero at the sides of the hole to a maximum behind the pin. In accordance with [11] no significative results have been observed for mixed or single configuration. Furthermore, Fig. 11 reveals a high amount of debonding among the layers. Additionally, pin-bearing failure was prompted by shear buckling, which indicates distortion of all the layers in phase with each other. The features suggested that the debonding area of a specified dimension starts to advance in correspondence with the maximum load. The layers buckled when the debonded span became dangerous, which, in turn, led to bearing failure. In general, no significant differences were detected among any of the tested samples.

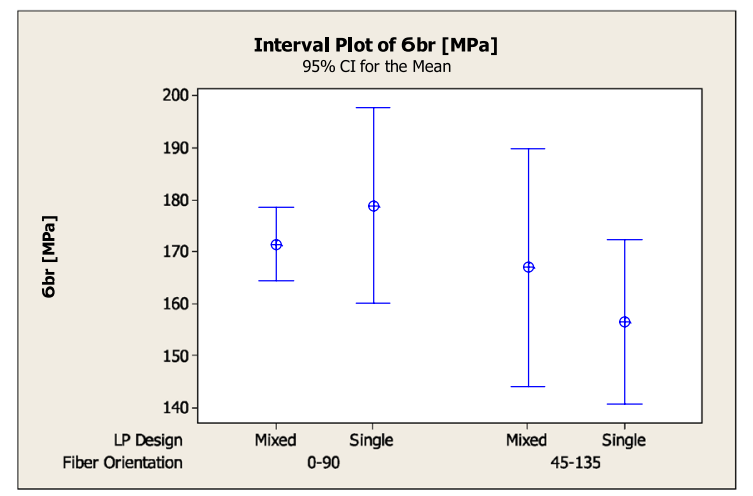

(a) $\sigma_{b r}$

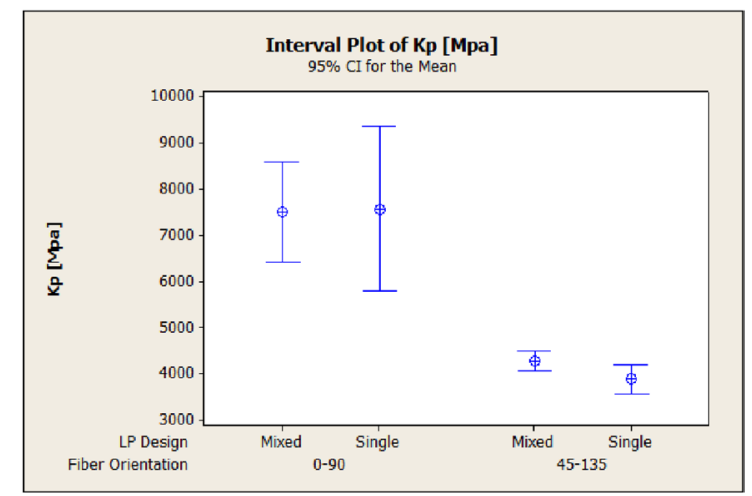

(b) $K_{p}$

Fig. 10 Main effects plot with $95 \%$ confidence interval for bearing strength (a) and stiffness b 


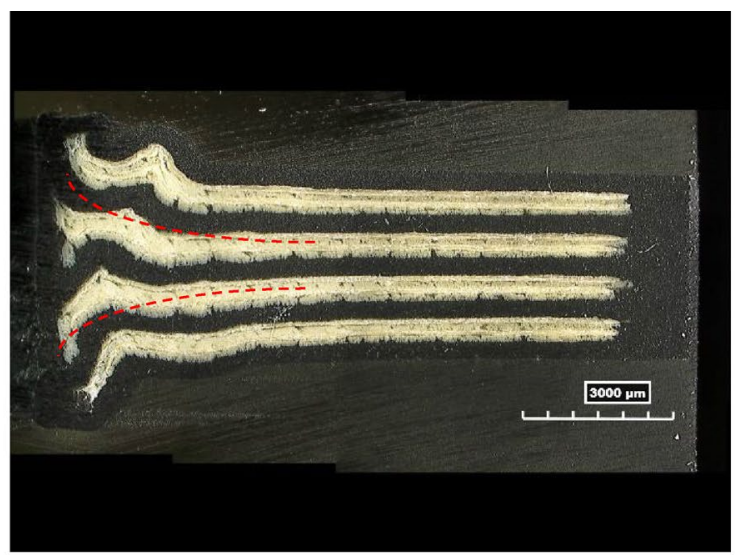

(a) Test 0_90_M

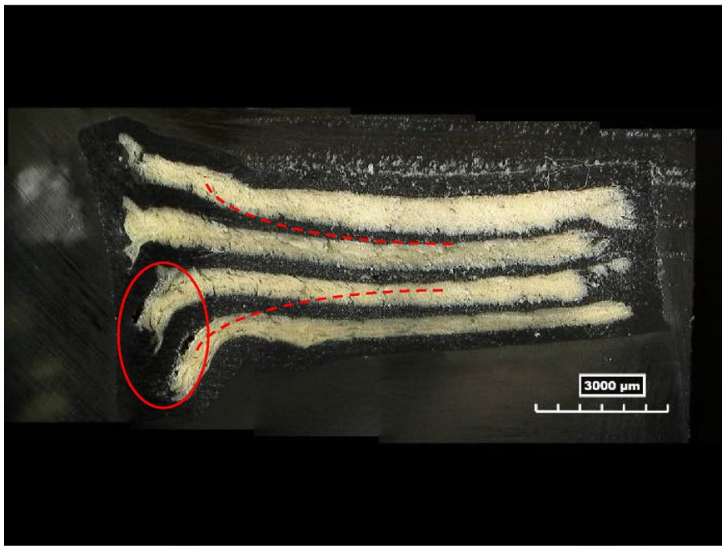

(c) Test 0_90_S

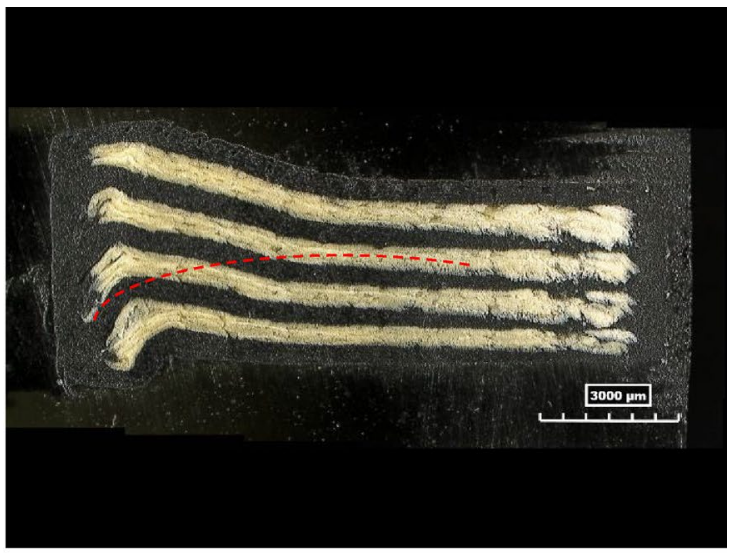

(b) Test 45_135_M

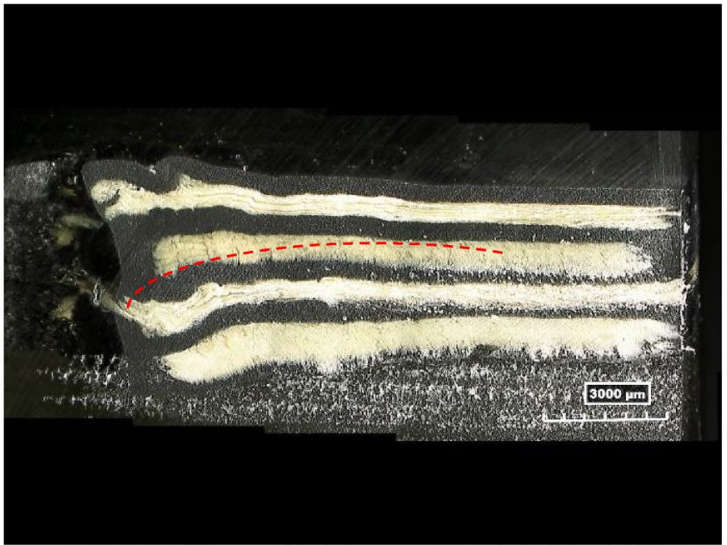

(d) Test 45_135_S

Fig. 11 Cross-sectional analysis with a $0^{\circ}$ cut in the region above the hole in (a) and $\mathbf{c}$ and $45^{\circ}$ cut in (b) and d

- The third experimental test indicated that the dimension of layer package inside the specimen did not affect bearing strength and stiffness. This result is in accordance with [12], wherein the analysis was conducted for tensile testing. On the contrary, because the bearing stress is not unidirectional the higher bearing strength was achieved in these test highlight an advantage when design parts with fiber oriented along more directions. This result can be useful because it provides high freedom in the design of reinforced parts and in fiber layer package size and distribution.

Finally, the results did not reveal a significant effect of the layer package design and position. Thus, it is possible to plot the bearing strength with respect to the stiffness of all experimental campaigns as a function of fibre orientation (Fig. 15).
The graph shows that it is possible to divide the results into four different quadrants as a function of the low or high values of $\sigma_{b r}$ or $K_{p}$. As expected, given its mechanical properties, the configuration without fibre exhibits lower sigma and lower stiffness (fibre orientation NO). However, it is interesting to observe that the main effect on the layer deposited in a direction parallel to the applied load results in a significant increase in stiffness (from 2000 to $10,000 \mathrm{MPa}$ ). The main effect of depositing fibre in two or more directions corresponds to increases in the bearing strength although significant stiffness variation is not measured (fibre orientation of $45^{\circ}$ vs. $45-135^{\circ}$ ). In conclusion, the configuration $0-90^{\circ}$ guarantees high values for both mechanical properties. The presence of layers with fibre orientations of $45^{\circ}$ and $135^{\circ}$ does not alter the mechanical behaviour and instead increases the dispersion of the results. 


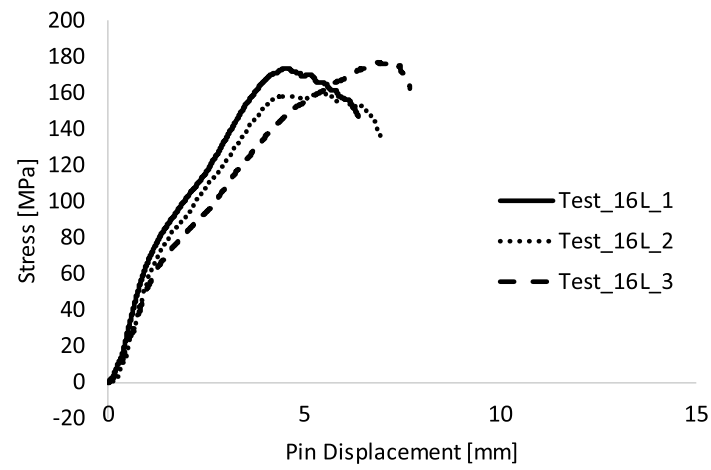

(a) Test_16L

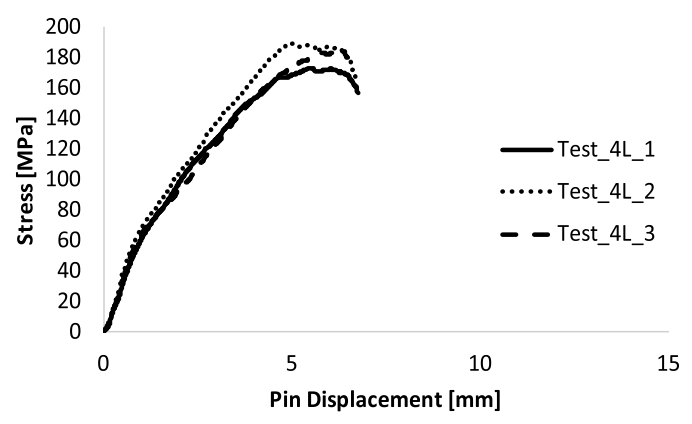

(c) Test_4L

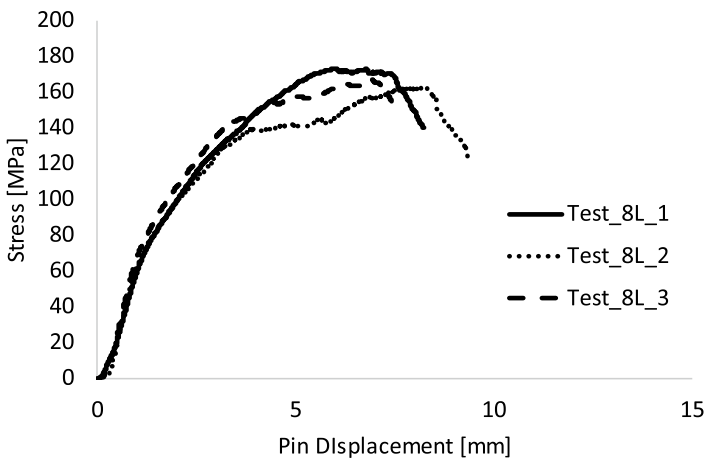

(b) Test_8L

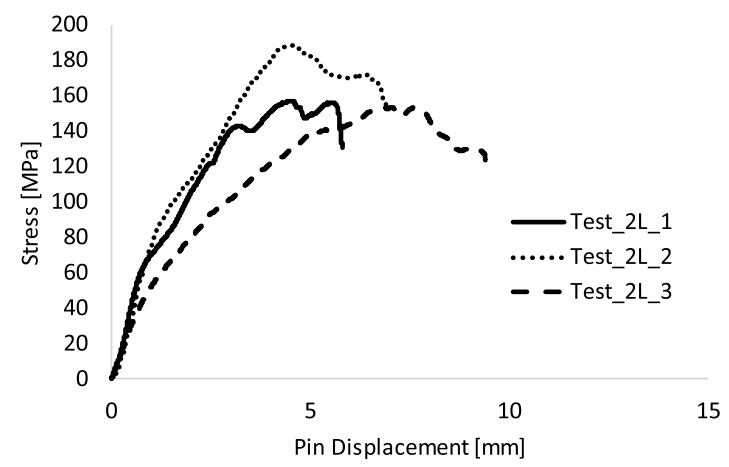

(d) Test_2L

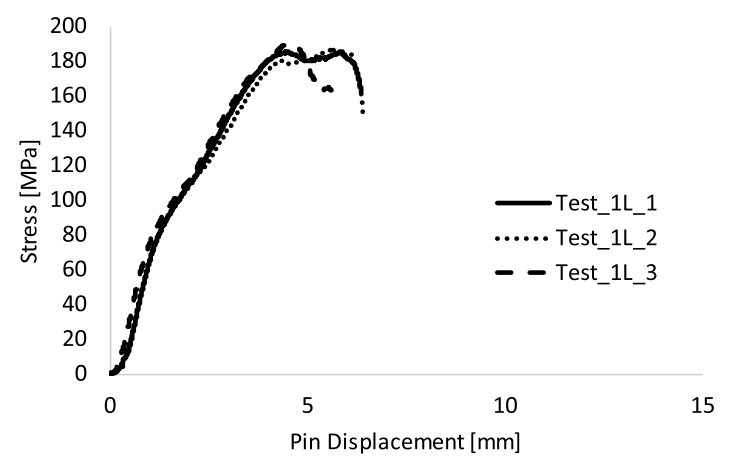

(e) Test_1L

Fig. 12 Main results for the third campaign pin bearing test

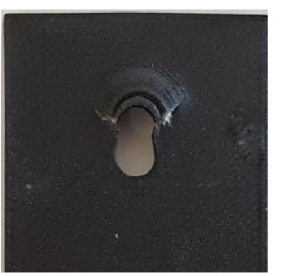

(a) Test_16L

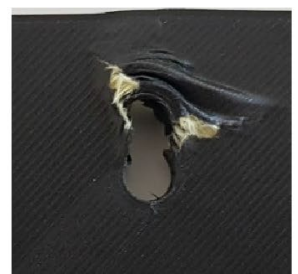

(b) Test_8L

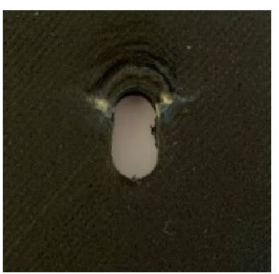

(c) Test_4L

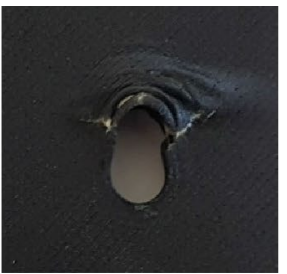

(d) Test_2L

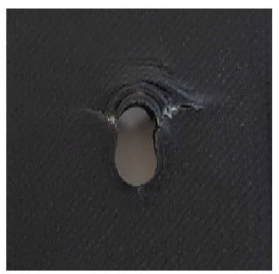

(e) Test_1L

Fig. 13 Third experimental test-magnified images of deformed specimens 
Table 7 ANOVA test results

\begin{tabular}{lll}
\hline Source & Parameter & $p$ value \\
\hline Layer package dimension & $\sigma_{b r}$ & 0.118 \\
& $K_{P}$ & 0.411 \\
\hline
\end{tabular}

\section{Conclusion}

In the study, it was analysed the mechanical behaviour of a composite material, which was reinforced with Kevlar and fabricated via fused filament fabrication, in a pin-bearing test. The results demonstrated that fibre orientation significantly affects mechanical behaviour as opposed to their position inside the specimen. Furthermore, with respect to pin-bearing behaviour, fibre layers in more than two directions do not improve bearing strength but increases part stiffness. On the contrary respect to the state of art, it was demonstrated that a multidirection strategy is preferred respect to a single one because in pin bearing the stress undergone along different direction. The results enhance knowledge on the use of CRFC materials fabricated via AM in construction of joints. In particular, the research establishes a technological window where, as a function of the desired bearing strength and stiffness it is possible to select the optimal sample configuration.

In the future it could be interesting evaluate the influence of samples geometry different values of the ratio hole diameter and edge distance (E/D) or hole diameter and width (W/D) on
Fig. 15 Sigma bearing versus stiffness as a function of fibre orientation

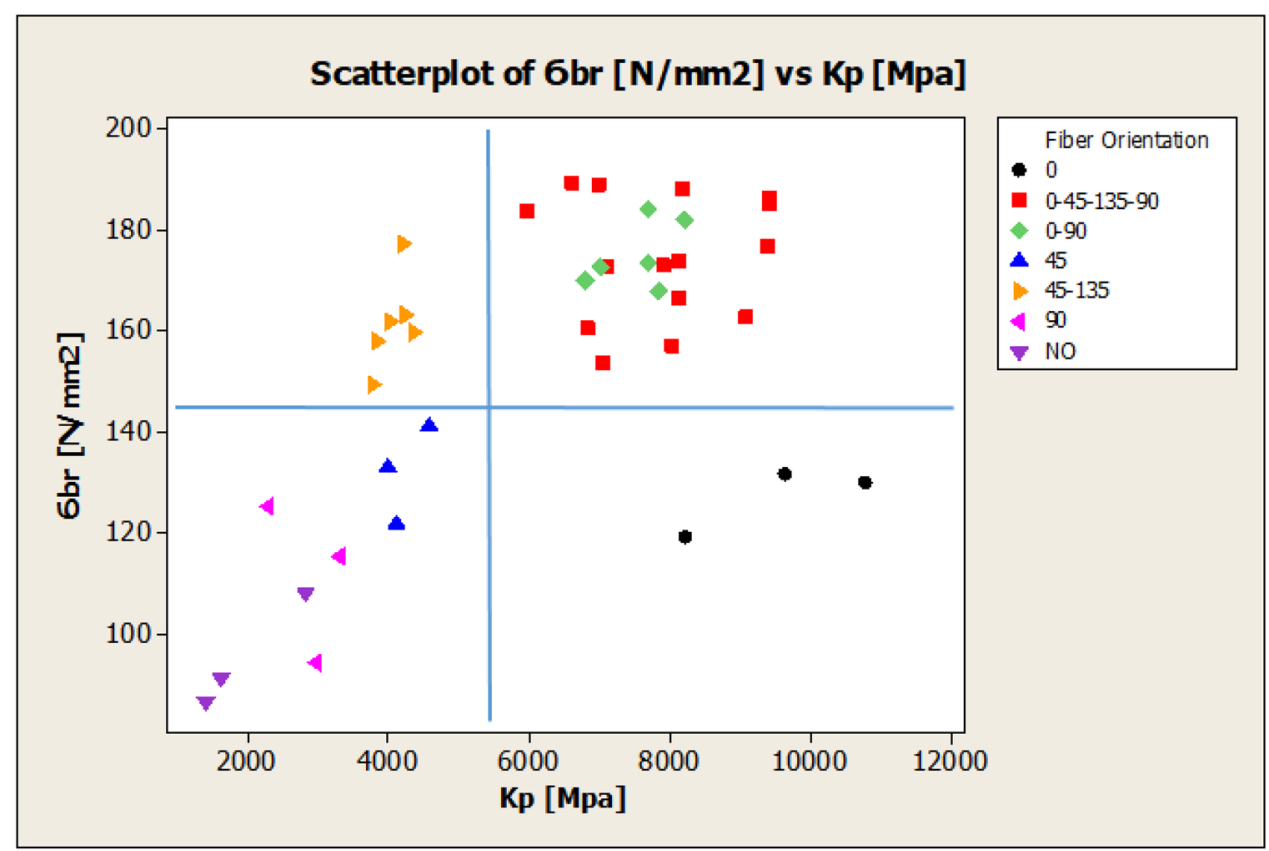

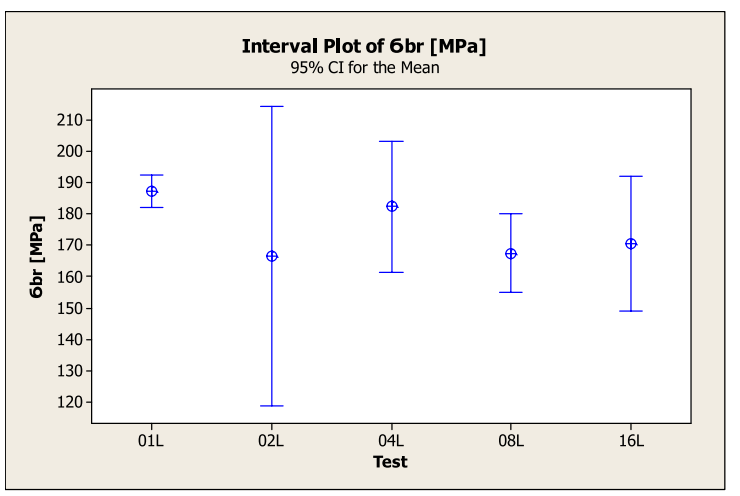

(a) $\sigma_{\mathrm{br}}$

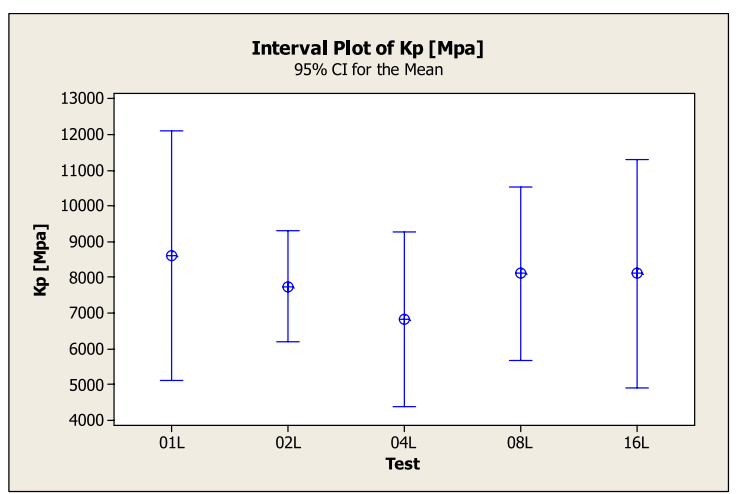

(b) $K_{p}$

Fig. 14 main effective plot with 95\% confidence interval of bearing strength (a) and stiffness (b) 
the bearing strength and failure to assess the bearing failure window.

Acknowledgements The authors acknowledge Giacomo Ranzini for his contribution to the sample design, Prof. Antonino Squillace and Prof. Elisabetta Ceretti for supervising research, and CIRTIBS at the University of Naples for allowing the use of Hirox microscope for the macrographs shown in the manuscript. The authors note that the present study was performed within the framework of the AITeM association.

\section{Declarations}

Conflict of interest The authors declare that they have no known competing financial interests or personal relationships that could have appeared to influence the work reported in this paper.

Open Access This article is licensed under a Creative Commons Attribution 4.0 International License, which permits use, sharing, adaptation, distribution and reproduction in any medium or format, as long as you give appropriate credit to the original author(s) and the source, provide a link to the Creative Commons licence, and indicate if changes were made. The images or other third party material in this article are included in the article's Creative Commons licence, unless indicated otherwise in a credit line to the material. If material is not included in the article's Creative Commons licence and your intended use is not permitted by statutory regulation or exceeds the permitted use, you will need to obtain permission directly from the copyright holder. To view a copy of this licence, visit http://creativecommons.org/licenses/by/4.0/.

\section{References}

1. Azwa ZN, Yousif BF, Manalo AC, Karunasena W (2013) A review on the degradability of polymeric composites based on natural fibres. Mater Des 47:424-442. https://doi.org/10.1016/j. matdes.2012.11.025

2. Chawla N, Shen Y-L (2001) Mechanical behavior of particle reinforced metal matrix composites. Adv Eng Mater 3(6):357-370. https://doi.org/10.1002/1527-2648(200106)3:6\%3c357::AIDADEM357\%3e3.0.CO;2-I

3. Zulkepli II, Mokhtar H, Aminanda Y, Shaik Dawood MSI, Rehan MSM (2019) Review of manufacturing process for good quality of composite assessment. IOP Conf Ser: Mater Sci Eng 488(1):012008. https://doi.org/10.1088/1757-899X/488/1/012008

4. Ben Amor I, Rekik H, Kaddami H, Raihane M, Arous M, Kallel A (2010) Effect of palm tree fiber orientation on electrical properties of palm tree fiber-reinforced polyester composites. J Compos Mater 44(13):1553-1568. https://doi.org/10.1177/0021998309 353961

5. Ford S, Despeisse M (2016) Additive manufacturing and sustainability: an exploratory study of the advantages and challenges. J Clean Prod 137:1573-1587. https://doi.org/10.1016/j.jclepro. 2016.04.150

6. Sood AK, Ohdar RK, Mahapatra SS (2010) Parametric appraisal of mechanical property of fused deposition modelling processed parts. Mater Design 31(1):287-295. https://doi.org/10.1016/j. matdes.2009.06.016

7. Brenken B, Barocio E, Favaloro A, Kunc V, Pipes RB (2018) Fused filament fabrication of fiber-reinforced polymers: a review. Addit Manuf 21:1-16. https://doi.org/10.1016/j.addma.2018.01. 002
8. Go J, Schiffres SN, Stevens AG, Hart AJ (2017) Rate limits of additive manufacturing by fused filament fabrication and guidelines for high-throughput system design. Addit Manuf 16:1-11. https://doi.org/10.1016/j.addma.2017.03.007

9. Dickson AN, Barry JN, McDonnell KA, Dowling DP (2017) Fabrication of continuous carbon, glass and Kevlar fibre reinforced polymer composites using additive manufacturing. Addit Manuf. https://doi.org/10.1016/j.addma.2017.06.004

10. Melenka GW, Cheung BKO, Schofield JS, Dawson MR, Carey JP (2016) Evaluation and prediction of the tensile properties of continuous fiber-reinforced 3D printed structures. Compos Struct. https://doi.org/10.1016/j.compstruct.2016.07.018

11. Parmiggiani A, Prato M, Pizzorni M (2021) Effect of the fiber orientation on the tensile and flexural behavior of continuous carbon fiber composites made via fused filament fabrication. Int J Adv Manuf Technol. https://doi.org/10.1007/s00170-021-06997-5

12. Van Der Klift F, Koga Y, Todoroki A, Ueda M, Hirano Y, Matsuzaki R (2016) 3D printing of continuous carbon fibre reinforced thermo-plastic (CFRTP) tensile test specimens. Open J Compos Mater. https://doi.org/10.4236/ojcm.2016.61003

13. Chen Y, Rios CO, Imeri A, Russell NA, Fidan I (2020) Investigation of the tensile properties in fibre-reinforced additive manufacturing and fused filament fabrication. Int J Rapid Manuf. https:// doi.org/10.1504/ijrapidm.2020.107734

14. Yang C, Tian X, Liu T, Cao Y, Li D (2017) 3D printing for continuous fiber reinforced thermoplastic composites: mechanism and performance. Rapid Prototyp J. https://doi.org/10.1108/ RPJ-08-2015-0098

15. Justo J, Távara L, García-Guzmán L, París F (2018) Characterization of 3D printed long fibre reinforced composites. Compos Struct. https://doi.org/10.1016/j.compstruct.2017.11.052

16. Blok LG, Longana ML, Yu H, Woods BKS (2018) An investigation into 3D printing of fibre reinforced thermoplastic composites. Addit Manuf. https://doi.org/10.1016/j.addma.2018.04.039

17. Peng Y, Wu Y, Li S, Wang K, Yao S, Liu Z, Garmestani H (2020) Tailorable rigidity and energy-absorption capability of 3D printed continuous carbon fiber reinforced polyamide composites. Compos Sci Technol. https://doi.org/10.1016/j.compscitech.2020. 108337

18. Dong G, Tang Y, Li D, Zhao YF (2018) Mechanical properties of continuous kevlar fiber reinforced composites fabricated by fused deposition modeling process. Procedia Manuf. https://doi.org/10. 1016/j.promfg.2018.07.090

19. Othman AR, Jadee KJ (2016) Specific bearing strength of bolted composite joint with different glass fiber reinforcement. ARPN J Eng Appl Sci 11:12039

20. Fiore V, Calabrese L, Scalici T, Bruzzaniti P, Valenza A (2018) Experimental design of the bearing performances of flax fiber reinforced epoxy composites by a failure map. Compos Part B Eng. https://doi.org/10.1016/j.compositesb.2018.04.044

21. Xiao Y, Ishikawa T (2005) Bearing strength and failure behavior of bolted composite joints (part I: experimental investigation). Compos Sci Technol. https://doi.org/10.1016/j.compscitech.2005. 02.011

22. Mounien R, Fagiano C, Paulmier P, Tranquart B, Irisarri FX (2017) Experimental characterization of the bearing behavior of 3D woven composites. Compos Part B Eng. https://doi.org/10. 1016/j.compositesb.2016.10.077

23. Ascione F, Feo L, MacEri F (2010) On the pin-bearing failure load of GFRP bolted laminates: an experimental analysis on the influence of bolt diameter. Compos Part B Eng. https://doi.org/10. 1016/j.compositesb.2010.04.001

24. Zhang H, Dickson AN, Sheng Y, McGrail T, Dowling DP, Wang C, Neville A, Yang D (2020) Failure analysis of 3D printed woven composite plates with holes under tensile and shear loading. 
Compos Part B Eng. https://doi.org/10.1016/j.compositesb.2020. 107835

25. Silvestri AT, Papa I, Rubino F, Squillace A (2021) On the critical technological issues of CFF: enhancing the bearing strength. Mater Manuf Process. https://doi.org/10.1080/10426914.2021. 1954195

26. Gower HL, Cronin DS, Plumtree A (2008) Ballistic impact response of laminated composite panels. Int J Impact Eng. https:// doi.org/10.1016/j.ijimpeng.2007.07.007

27. Leigh Phoenix S, Porwal PK (2003) A new membrane model for the ballistic impact response and V50 performance of multiply fibrous systems. Int J Solids Struct. https://doi.org/10.1016/ S0020-7683(03)00329-9

28. Porwal PK, Phoenix SL (2005) Modeling system effects in ballistic impact into multi-layered fibrous materials for soft body armor. Int J Fract. https://doi.org/10.1007/s10704-005-3993-9

29. Bakis CE, Bank LC, Brown VL, Cosenza E, Davalos JF, Lesko JJ, Machida A, Rizkalla SH, Triantafillou TC (2002) Fiber-reinforced polymer composites for construction-State-of-the-art review. J Compos Constr 6(2):73-87. https://doi.org/10.1061/(ASCE)10900268(2002)6:2(73)
30. Papa I, Silvestri AT, Ricciardi MR, Lopresto V, Squillace A (2021) Effect of fibre orientation on novel continuous 3D-printed fibre-reinforced composites. Polymers (Basel). https://doi.org/10. 3390/polym 13152524

31. ASTM D5961, D5961M-13 (2013) Standard test method for bearing response of polymer matrix composite laminates. Am Soc Test Mater. https://doi.org/10.1520/D5961

32. Cameron CJ, Larsson J, Loukil MS, Murtagh T, Wennhage P (2021) Bearing strength performance of mixed thin/thick-ply, quasi-isotropic composite laminates. Compos Struct. https://doi. org/10.1016/j.compstruct.2020.113312

33. Slagter WJ (1992) On the bearing strength of fibre metal laminates. J Compos Mater. https://doi.org/10.1177/002199839202601 705

34. Marshall IH, Arnold WS, Wood J, Mousley RF (1989) Observations on bolted connections in composite structures. Compos Struct. https://doi.org/10.1016/0263-8223(89)90051-2

Publisher's Note Springer Nature remains neutral with regard to jurisdictional claims in published maps and institutional affiliations. 